\title{
Profiling Neurolanguage Coaches Worldwide - A Case Study
}

\author{
Dimitris Zeppos ${ }^{1, *}$ \\ ${ }^{1}$ Tutor at Hellenic Open University, Patras, Greece \\ *Correspondence: 68 Vas. Sofias Street, GR-19001 Keratea, Greece. Tel: 30-6974-649-981. E-mail: zepposd@sch.gr \\ /zepposd@gmail.com
}

Received: October 16, 2014 Accepted: November 8, $2014 \quad$ Online Published: November 20, 2014

doi:10.5430/wje.v4n6p26 URL: http://dx.doi.org/10.5430/wje.v4n6p26

\begin{abstract}
Neurolanguage Coaching ${ }^{\mathrm{TM}}$ is a new approach of diversified personalized language instruction utilizing modern insights of neuroscientific and pedagogic theories. This paper addresses the issue of profiling educational experts, who utilize these theories to coach language learners through their language acquisition journey, by means of setting and facilitating specific characteristics, common to those educationers. Findings of an on-line qualitative questionnaire are quantified to allow for the generalization of these characteristics in a case study of Certified Neurolanguage Coaches in order to establish an innovative descriptive tool for an upcoming professional group. Characteristics are formulated according to literature and statistical verification and a profile description of Neurolanguage Coaches is proposed.
\end{abstract}

Keywords: neurolanguage; neuroscience; coaching; profiling; foreign language; TFL

\section{Introduction}

\subsection{Theoretical Background}

Over the last years a new trend seems to be developing: language coaching and teachers/trainers calling themselves "language coach" (Paling, 2013a). Like every emerging educational discipline, "coaching" is struggling with problems of definition (Ives, 2008). As Stober and Grant (cited in Ives, 2008, p. 100) state,

"goal-oriented approaches to coaching are typically brief and aim for relatively immediate results, therapeutic and personal-development approaches tend to go deeper and are more prolonged. While coaching has been immeasurably enriched by the injection [of] new ideas and techniques, it has led to increased confusion about the precise nature of coaching and what it is designed to achieve. Consequently, coaching has become increasingly difficult to define".

Further to this, finding a satisfactory or even remotely decisive definition of what exactly a "language coach" is, presents even more difficulties due to the fact that this specific professional group obviously originates from the broader teacher setting and therefore tends to be esteemed as a "branch" of language teaching experts.

The practice of "language coaching" is known for quite some time now and there have been numerous papers describing coaching "procedures" (e.g. Biswas-Diener, 2009; Greenman, 2004; Griffiths \& Campbell, 2009; ICF Foundation, n.d.; Rosinski, 2003; Sherris, 2010) and the coaching "profession" (e.g. Canrinus, Helms - Lorenz, Beijaard, Buitink, \& Hofman, 2011; Grant \& Unit, 2006; Hamlin, Ellinger, \& Beattie, 2009). Nonetheless, specific descriptors and profiling efforts especially designed for the "language coach" do not seem to have been carried out to date.

This paper deals with this deficiency by proposing a descriptive, i.e. qualitative, "language coach profile" based on information collected through data analysis derived from input gathered through a structured on-line questionnaire presented to participants of "language coach training" sessions carried out by Efficient Language Coaching, who have received accreditation for this very specific teaching, training and mentoring procedure.

The data collected proposes a "profile" of "language coaches" as regards their demographic, educational and professional specifications as well as their professional aspirations and pedagogical ambitions. The scope of the paper is to create a first attempt at describing this new life-long educational profession in a way that would allow for 
new members to decide to embark on the voyage of turning their every-day language teaching practice into a procedure of language coaching as well as for interested parties to seek for specialist "language coaches" according to profiled specifications which would agree with their special requirements and to consider whether "language coaches" would cover their need for specific language training procedures.

\subsection{Research Problem}

In order to achieve such a profiling, this paper tries to establish a specific descriptive data set answering to the following questions:

- What are the demographic characteristics of certified language coaches?

- Can the educational and professional background of language coaches be templated?

- How do language coaches describe their aspirations and ambitions regarding their practice?

The following chapters analyze the procedure, input and findings of the survey carried out on-line from August 1 through September 21, 2014, in cooperation with Efficient Language Coaching, a training company located in Europe which certifies language coaches according to training specifications and framework set out by the International Coaching Federation in the USA.

\subsection{Literary Review and Definitions of Terms}

In order to create a sound framework of terms used in this study, the following chapter will declare all terminology used throughout this paper so that the use of terms is common to the reader. This means that definitions given in this paper are subject to the understanding of its content only and do not assume generality, as far as the use of the same term in other contexts is concerned.

\subsubsection{Group Profiling of Foreign Language Coaches}

The term "profiling" produces difficulties in definition, if associated with the description of a specific group of people of common interest in the field of education. As mentioned on the Education Resources Information Center web page ("ERIC - Thesaurus - Profiles," n.d.), profiles are "summary descriptions, often presented in diagrams or charts, that indicate the significant features of an individual, group, process, etc".

Almost all research done on humanity or social sciences includes some kind of - usually demographic - profiling, (e.g. Canrinus, Helms - Lorenz, Beijaard, Buitink, \& Hofman, 2011; Fichtner \& Chapman, 2011; Kovacic, 2012; North, 2009; Onyancha, 2010). In the past, various efforts have been made to set up and facilitate electronic profiling systems for teachers and students alike. In this research area, a number of software solutions and on-line database resources have been proposed which are intended to lead to a collective profiling system for the assessment of teachers and their respective placement in teaching positions of their institutions (Rahman, 2013). Nevertheless, these efforts focus on post- or ad hoc teaching assessment and related teacher evaluation by school advisors. They do not facilitate the description of teacher categories and their respective characteristics for specialized clusters of expertise, therefore such systems - up for now - cannot assist in setting up and describing specific teacher-group characteristics in advance.

While trying to identify professional profiling in literature it is easy to discover that

“... the term refers to rather different things that do not necessarily share common characteristics, but are related to each other in important ways. Pertinent examples are: (1) the term is used both for the construction and for the application of profiles; (2) group profiles have very different characteristics and a different impact from personalized profiles" (Hildebrandt, 2005).

Since group profiling is an instrument of identifying characteristics common to a number of people making up or belonging to a specific interest group, the definition given by Hildebrandt (ibid) for group profiling as "...the process of establishing that a subject is an element of a specific set of subjects, by means of the set of correlated attributes that defines the group" shall be used as a base line and will be adapted accordingly for determining and defining the special scope of the term in this paper.

Thus, according to the previously mentioned dedicated literature review and the aims of this study, the teacher group profile of Language Coaches produced through data mining techniques and discussed in this paper is regarded as a set of descriptive characteristics which portray a specific professional group engaging in activities leading to the teaching and coaching of foreign languages under special conditions. 


\subsubsection{Neurolanguage}

As an initial step it is important to clarify terminology to avoid confusion and create clear delineations of what "neurolanguage coaching" really is and what it really comprehends.

As quoted in Wikipedia

"Neurolinguistics is the study of the neural mechanisms in the human brain that control the comprehension, production, and acquisition of language" whereas "Neuroscience is the scientific study of the nervous system...... At the systems level, the questions addressed in systems neuroscience include how neural circuits are formed and used anatomically and physiologically to produce functions such as reflexes, multisensory integration, motor coordination, circadian rhythms, emotional responses, learning, and memory."

The definition of the approach advocated by ELC as "neurolanguage coaching" is obviously deriving from the scientific findings and research carried out not only in Neurolinguistics but also with the added dimension of Neuroscience, in particular with emphasis on how new neural networks and synaptic firing can occur/and form while learning a language (Paling, 2013a, p. 18).

In order to establish a common communication base, a definition of "neurolanguage" through an exploration of "neurolinguistics" and "neuroscience" as proposed by recent literature and adapted to the general layout of this research paper is attempted.

As cited by Nergis (2011, p. 143), "Neurolinguistics mainly investigates linguistic development of normally developing subjects [...]", while Lebrun (1983, p. 243), on the other hand, defines Neurolinguistics as being "different from linguistics in that it studies language users rather than language: it analyzes deviant language behavior not for its own sake but with a view to discovering the neurological mechanisms underlying the deviance. $[\ldots] "$.

The definition given by the L. Menn (n.d.) on the site of the Linguistic Society of America, defines Neurolinguistics as "the study of how language is represented in the brain: that is, how and where our brains store our knowledge of the language (or languages) that we speak, understand, read, and write, what happens in our brains as we acquire that knowledge, and what happens as we use it in our everyday lives."

According to the relative literature in conjunction with the scope of this paper, "neurolanguage" shall be regarded as the scientific research area which is interested in not only the study of the neural mechanisms in the human brain that control the comprehension, production, and acquisition of language in order to both fulfil basic or advanced communication tasks and acquire new language structures but also recent neuroscientific findings of neuron synapsis, neuroplasticity and neural networks mechanism.

In essence, the emergent area of "neurolanguage" does in fact comprise the totality of neurolinguistics as well as the new aspect of neuroscience relating to how the brain functions, learns and memorizes in relation to language acquisition and communication.

\subsubsection{Coaching}

As the term and consequently the tools and techniques beneath it are a rather new facet in inter-personal foreign language education efforts, it is more than anticipated that there are a number of different definitions of the term and its philosophy. In the following we will review some of these definitions, stating though that the list is far from being complete. We will refer to the reviewed literature beginning from the general descriptions and narrowing these down towards the educational sector and furthermore to foreign language coaching.

As R. Biswas-Diener (2009) mentions in his article, the profession of "personal coach" is rather "new and unlicensed", meaning that in the beginning of the profession, there has been no regulatory body which would oversee both qualification and practices of those who endeavored in the approaches advocated by "coaching" strategies and practices. Even though Biswas-Diener refers to personal coaching under the specifications of clinical psychology interventions, his description of coaching defines personal coaching as "[...] a professional relationship in which coaches work with clients to facilitate experiential learning and improve functioning and performance, often in the context of working toward specific goals." (ibid, p. 544)

The International Coach Federation (ICF), which is the first relevant professional governing body, defines coaching as partnering with clients in a thought-provoking and creative process that inspires them to maximize their personal and professional potential. Coaching honors the client as the expert in his/her life and work and believes that every client is creative, resourceful, and whole (ICF Foundation, n.d.). 
If talking about teacher development and further education, coaches are defined as teacher educators whose "coaching includes observing teachers and students interact in classroom settings, collecting data on those interactions, and initiating confidential, private, and sometimes small-group discussions with observed teachers" (Sherris, 2010). In this context, coaching is defined

"as a type of assistance provided to individual teachers and sometimes small groups of teachers that addresses complex challenges to learning, teaching, and assessment of language and opens teachers to exploratory, self-critical, and reflective dimensions of interaction through a process of inquiry that is co-constructed and dialogic." (Sherris, Bauder, \& Hillyard, 2007; Sherris, 2009)

Another aspect of coaches is incorporated in the term "community coaches" (Dingen, n.d.). They are described as educators who have attained the skills to "build [...] awareness in their students of the potential impact of their communication style on business partners."

In reference to transferring cultural values through coaching activities, Rosinski $(2003$, p. 2) defines coaching as an "art of facilitating the unleashing of people's potential to reach meaningful, important objectives" in order to facilitate the coachee to increase his/her awareness of cultural differences and to deal productively with challenging differences when they arise.

Paul Caccia refers to "Linguistic Coaching" for beginning teachers as a technique where "all speaking and listening arise from a pre-existing background of beliefs, attitudes, experiences, and emotions", which can be supported by "identifying the performance to be improved, establishing the interpretations behind the performance and intervening by coaching for new interpretations and actions." (Caccia, 1996, pp. 18-19)

Focusing on teacher development based on peer-coaching experiences, Showers and Joyce (1996) reach the conclusion that "Coaching provides an opportunity to reflect on a session and consider, in a supportive climate, why an approach did or did not work and how it might be changed or refined."

Ives (2009) argues in his work that coaching can be distinguished in three main categories, namely "goal-oriented interventions", "therapeutic approaches" and "personal-development approaches", thus exemplifying the difficulties which exist in appointing a specific and widely acknowledged definition to the uprising pedagogical approach.

Incorporating "neurolanguage" aspects of language coaching, Paling (Paling, 2013a) describes language coaching as implementing "... a code of ethics and principles which are well suited to the corporate and business world, bringing trust, intimacy and confidentiality into sessions". She therewith sets a new discipline area for business coaches, where "language coaching is geared towards tailor-making and adapting to the coachee him/herself and definitely veers towards a much more individualized and personalized process".

This aspect of how modern approaches to coaching are reflected on "traditional" language teaching is demonstrated in the comparison table, which has been adapted for the purpose of this paper, based on Paling's (Paling, 2013a) differentiation of languages coaches and teachers:

Table 1. Comparison between Characteristics of NLC and Traditional Language Teaching

\begin{tabular}{|c|c|}
\hline Neurolanguage Coaching (NLC) & Language Teaching \\
\hline 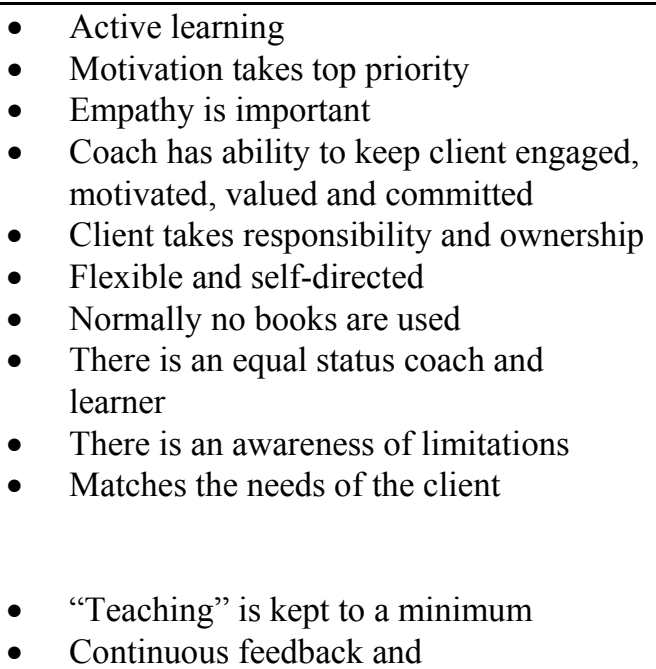 & $\begin{array}{l}\text { - It could sometimes be described as mainly a } \\
\text { one-way process } \\
\text { - Book related - following chapters and the order } \\
\text { of language learning books } \\
\text { - } \quad \text { Often limited to the materials/books used } \\
\text { superior status } \\
\text { - The relationship between the teacher and the } \\
\text { learner is often not so close nor is it a realistic } \\
\text { or personalized experience } \\
\text { - Often encompasses a more formal approach } \\
\text { - Instructive and mandatory }\end{array}$ \\
\hline
\end{tabular}




\begin{tabular}{|c|c|}
\hline $\begin{array}{l}\text { acknowledgement } \\
\text { - Stimulates reflexion } \\
\text { Coach has the ability to adapt to the } \\
\text { client } \\
\text { - Client focused and tailor-made } \\
\text { - One objective is to maximize the } \\
\text { potential of the learner } \\
\text { Focus on cost effectiveness }\end{array}$ & 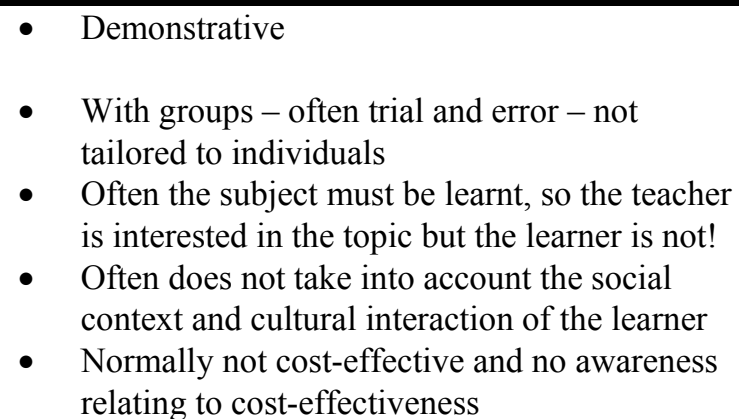 \\
\hline
\end{tabular}

While Paling cautiously mentions that none of the above characteristics are declared in a negative sense, the comparison of the two columns clearly demonstrates a differentiation in the philosophy of language coaches in order to approach their own professional goals.

The obvious main difference, which can be deducted, is that coaches aim at self-regulated learning (Baird, Hopfenbeck, Newton, Stobart, \& Steen-Utheim, 2014; Halim, Ali, \& Yahaya, 2011; Juwah et al., 2004; Kormos \& Csizér, 2014; Yukselturk \& Yildirim, 2008; Zampetakis, Bouranta, \& Moustakis, 2010) as opposed to the role of a traditional language teacher, where the teacher is identified as the sole bearer of knowledge who also has the responsibility and ownership (Paling, 2013a) of the knowledge acquired and the pathway to this acquisition.

Finally, Aaron Myers (n.d.) offers a definition of "language coach" in his web-site, citing that

"Language coaching is similar to any other coaching situation whether it be a basketball coach, a personal trainer or a life coach. A coach's job is not to play the game or do the workout or live the life of the athlete or person, but rather to help create training situations, offer feedback, provide encouragement and give direction to help facilitate the most effective and efficient learning program for each individual."

Furthermore, for this paper a neurolanguage coach is a specialized language educator, who utilizes methods, models, tools and approaches as well as neuroscience and neurolinguistics to obtain the best possible foreign language learning results for his/her customer through methods of non-directive (Ives, 2009; Paling, 2013b) encouraging, strengthening, personal development and other techniques described by coaching processes and neuroscientific findings alike, linked to pedagogic goals.

\subsubsection{Neurolanguage Coaching}

The approach introduced by ELC is based on findings and research done in the field of Neuroscience, in correlation to foreign language learning, as documented in various research papers. According to one research study (Schoen, 2013), "Neuroscience is the study of how the mind and body interact to give rise to behavior, and it's methods are aimed at studying these relationships".

As Paling (2014, p. 19) defines,

"Neurolanguage coaching has nothing to do with psychotherapy, neurolinguistic programming or any other psychological process. Underlying neurolanguage coaching has to be and is the transmission of language knowledge - the teaching process - which is reinforced, focused, invigorated and personalized through the coaching aspects, then fortified and consolidated with the neuroscientific aspects."

Keeping in mind the very wide variety of definitions on coaching, for this paper neurolanguage coaching shall be therefore regarded as the act of promoting language learning through specific novel procedures promoting personal development, self-regulated learning methods, neuroscientific support and goal-oriented approaches aiming at the acquisition of the foreign language by means other than the traditional language teaching.

\section{Method}

In order to establish the necessary data to define the profile of a characteristic "neurolanguage coach", this paper is based on results gathered through a semi-structured anonymous on-line questionnaire published and administered on a privately owned web-site. The questionnaire was running for a specific time span (two months between July and September 2014) and addressed graduates of "neurolanguage coach" certification training held both on-line or teleconference together with face to face. ("blended learning" - (Chen \& Jones, 2007; Comas-Quinn, 2011; Kirwin, 
Swan, \& Breakwell, 2009; Tayebinik \& Puteh, n.d.; Zeppos, 2014).

\subsection{Questionnaire, Rubrics and Categories}

The online questionnaire consisted of a series of open-ended and multiple choice questions addressing various aspects of the character, personal and professional development, assumptions, aspirations and ambitions of the research subjects. In order to offer a complete insight of the structure and logic of the questionnaire, the following sections of this paper briefly describe both the contents and the scope of the questions presented online.

The laid out rubrics and categories derived from extensive literature research on qualitatively assessing questionnaires, while the individual characteristics are a result of combining personal characteristics mentioned in the respective literature.

In further detail, the following characteristics, which were taken from the respective literature review, were addressed in the questionnaire, besides the typical data gathered in quantitative surveys, such as demographic data and educational and professional background of the subjects. In brackets are the original authors of the characteristics mentioned.

\section{Coaching Aspirations}

- being a role model (Bennet, 2003, p. 3)

- assisting in conceptual / theoretical learning (Bennet, 2003, p. 3)

- helping to set learning goals (Bennet, 2003, p. 3)

- being a resource person (Bennet, 2003, p. 3)

- evaluating progress (Bennet, 2003, p. 3)

- wants to coach as a day-to-day function (Stewart, Palmer, Wilkin, \& Kerrin, 2008, p. 33)

- wants to function as an executive coach (Stewart et al., 2008, p. 33)

- wants to implement ICT techniques in language learning (Myers, n.d.)2.3 Sampling Procedures

\section{Coaching Ambitions}

- make high-functioning individuals perform even better (Biswas-Diener, 2009, p. 546)

- willing to share ideas and expectations about the roles of the coach and coachee (Bennet, 2003, p. 3)

- encourage and enable learners to take more responsibility for their own development (Bennet, 2003, p. 3)

- consider him/herself as a "teacher" or "instructor" (instructor role - Ives, 2008, p. 105)

- consider him/herself to be "advice-giving" (advising role - Ives, 2008, p. 100)

- considers his/her interventions to be based on values (Jackson, 2005, p. 51)

- considers his/her interventions to be based on procedure (Jackson, 2005, p. 51)

- uses systematic methodology in coaching procedures (Jackson, 2005, p. 56)

- uses flexible personal methodology in coaching procedures (Jackson, 2005, p. 56)

\subsection{Procedure}

The research was carried out with the use of an on-line survey tool situated on a 24/7 multiuser platform of the Greek School Network www.sch.gr. The questionnaire was set to automatically close at a specified date to restrict the duration of the survey and therefore allow for a specific time-window for the data to be gathered.

Participants were able to submit their answers by responding to the various types of input questions, which varied from closed-type to open type and Likert-type items.

After the pre-determined date the questionnaire was closed and no further responses could be submitted. The resulting data was then downloaded from the on-line server in order to be analyzed by means of simple statistical breakdown in order to establish percentages that could be generalized for the population under study.

\subsection{Participants and Restrictions}

In order to carry out the on-line survey, a decision had to be made as to which population to target. Since the use of neuroscientific research findings and approaches in Foreign Language Coaching is rather new, as shown in the literary review, it was decided to aim at coaches already certified according to these specific descriptors. 
After seeking respective information, Rachel Paling, ACC and Managing Director of "Efficient Language Coaching", offered to contribute to the study by providing numerical and initial training-specific information about the language coaches certified through their on-line or face to face certification courses.

According to the archives of ELC, a total of 54 individuals of various countries, age groups and vocational background, had been certified between 2013 and mid-summer of 2014. Prerequisite for participating in the training course is to either be a qualified language teacher (TOEFL, CELTA etc.) or to be able to produce evidence of at least two to five years of FL teacher experience. Thus, a total population of $n_{p}=54$ was defined for the purpose of this research, narrowing the population down to those individuals that have been certified by this specific training institution and accredited by ICF.

The survey produced a total of 21 completed questionnaires by the date it automatically shut down. Therefore, the sample population of this study reached $n=21$, which represents $39 \%$ of the total population $\left(n_{p}\right)$ of ELC certified language coaches. In this way a representative sample of the total research population was established.

At this point it has to be mentioned that the data collected was intentionally aimed specifically at those coaches certified by ELC and accredited by the ICF. Therefore this paper is to be considered as a case study of a specific language coach certification institution which follows an innovative neuroscientific approach, and no other certifying bodies, if there are any, have been taken into account.

This calls for a further investigation to determine if there are other institutions that offer certification for language coaches using techniques influenced by neuroscientific findings and to survey their language coaches' profile for further comparison and generalization.

\section{Findings and Discussion}

A total of 21 questionnaires were completed, which produced a survey body of $n=21$. After analyzing the data input, the following raw data was gathered and categorized according to the initial research problems stated.

\subsection{Demographic Data}

Out of 21 answers, $15(71,43 \%)$ were women, while the remaining 6 responses $(28,57 \%)$ were men.

Six individuals $(28,57 \%)$ stated that they belonged to the first age group designated between 26 and 35 years, followed closely by five responses $(23,81 \%)$, who stated to be within the third age group of 46 to 55 years and another five responses $(23,81 \%)$ belonging to the fourth age group between 56 and 65 . Four individuals $(19,05 \%)$ declared to belong to the second designated age group of 36 to 45 years, while the remaining one response $(4,76 \%)$ was allocated at the age group of $65+$.

Most of the research individuals stated that their country of origin was the United Kingdom (8 responses, 38,10\%), while three individuals $(14,29 \%)$ originated from Costa Rica and two responses $(9,52 \%)$ came from the USA. Other countries mentioned were Canada, the Czech Republic, Germany, Hungary, Italy, Japan, Poland and the Republic of Ireland.

Table 2. Countries of Origin of NLCs

\begin{tabular}{lrr}
\hline Country & Count & Percent \\
\hline Canada & $\mathbf{1}$ & $\mathbf{4 , 7 6 \%}$ \\
Costa Rica & $\mathbf{3}$ & $\mathbf{1 4 , 2 9 \%}$ \\
Czech Republic & $\mathbf{1}$ & $\mathbf{4 , 7 6 \%}$ \\
Germany & $\mathbf{1}$ & $\mathbf{4 , 7 6 \%}$ \\
Hungary & $\mathbf{1}$ & $\mathbf{4 , 7 6 \%}$ \\
Italy & $\mathbf{1}$ & $\mathbf{4 , 7 6 \%}$ \\
Japan & $\mathbf{1}$ & $\mathbf{4 , 7 6 \%}$ \\
Poland & $\mathbf{1}$ & $\mathbf{4 , 7 6 \%}$ \\
Republic of Ireland & $\mathbf{1}$ & $\mathbf{4 , 7 6 \%}$ \\
United Kingdom & $\mathbf{8}$ & $\mathbf{3 8 , 1 0 \%}$ \\
USA & $\mathbf{2}$ & $\mathbf{9 , 5 2 \%}$ \\
& $\mathbf{2 1}$ & $\mathbf{1 0 0 \%}$ \\
\hline
\end{tabular}




\subsection{Educational Data}

The responses about the educational background of the sample population disclosed a number of interesting observations. Of the 21 completed responses, 20 declared their basic educational status. The following table summarizes their categorized responses according to the initial questionnaire categories (percentage rounded to nearest integer) and sums up occurrences of similar background data.

Table 3. Educational Background (discriptive)

\begin{tabular}{|c|c|c|c|c|}
\hline $\begin{array}{c}\text { Education Category of the } \\
\text { questionnaire }\end{array}$ & Comments submitted $^{l}$ & Count & Sum & Percentage \\
\hline $\begin{array}{l}\text { pre-University degree or } \\
\text { certificate }\end{array}$ & $\begin{array}{c}\text { I completed } 2 \text { years of University studies } \\
\text { No comment }\end{array}$ & $\begin{array}{l}1 \\
1\end{array}$ & 2 & $10 \%$ \\
\hline $\begin{array}{l}\text { Holder of an elementary } \\
\text { University Degree - } \\
\text { University Certificate other } \\
\text { than BA }\end{array}$ & $\begin{array}{c}\text { Qualified nurse and midwife } \\
\text { Italian, Spanish, Brazilian, Portuguese } \\
\text { Certification }\end{array}$ & 1 & 2 & $10 \%$ \\
\hline $\begin{array}{l}\text { Holder of an elementary } \\
\text { University Degree - e.g. BA }\end{array}$ & $\begin{array}{c}\text { BA (Open) English and German } \\
\text { Licenciatura (BA) in Business } \\
\text { Administration } \\
\text { French degree, Anglo-American studies and } \\
\text { Applied Linguistics } \\
\text { BA (Honours) } \\
\text { No comment } \\
\end{array}$ & $\begin{array}{l}1 \\
1 \\
2\end{array}$ & 6 & $29 \%$ \\
\hline $\begin{array}{l}\text { Holder of an advanced } \\
\text { University Degree - PhD or } \\
\text { equivalent }\end{array}$ & $\begin{array}{c}\text { I have a degree of the "Rheinisch } \\
\text { Westfälische Technische Hochschule } \\
\text { Aachen" in material science and metallurgy } \\
\text { (Dipl-Ing.) } \\
\text { postgraduate diploma in law }\end{array}$ & 1 & 2 & $10 \%$ \\
\hline $\begin{array}{l}\text { Holder of an advanced } \\
\text { University Degree - MA } \\
\text { (Master or Magister Artium } \\
\text { or Magister) }\end{array}$ & $\begin{array}{c}\text { Holder of MS in TESOL and MA in } \\
\text { Communication, a PhD candidate in } \\
\text { Curriculum and Instruction } \\
\text { MA in English and TESOL } \\
\text { MA in English Linguistics } \\
\text { master of History and Masters of Translation } \\
\text { BA and MA } \\
\text { Master in Education }{ }^{2} \\
\text { No comment }\end{array}$ & $\begin{array}{l}1 \\
1 \\
1 \\
1\end{array}$ & 8 & $38 \%$ \\
\hline No Comment & & & $\frac{1}{21}$ & $\begin{array}{l}5 \% \\
100 \%\end{array}$ \\
\hline
\end{tabular}

As can be seen in the Table 3, the majority of the responders hold a higher University degree, although two do not clarify the content of their degree and another two do not give any description. Nevertheless, $43 \%$ of the subjects hold a (higher) degree in Humanity, while 14\% hold a Degree in Arts.

Table 4. Educational Background (aggregation)

\begin{tabular}{lcc}
\hline Basic Degree in ... & Count & Percentage \\
\hline Humanities (general, except education) & $\mathbf{2}$ & \\
Education (general) & $\mathbf{1}$ & $\mathbf{4 3 \%}$ \\
Language and / or Literature & $\mathbf{6}$ & \\
\hline Arts (general) & $\mathbf{3}$ & $\mathbf{1 4 \%}$ \\
No description & $\mathbf{3}$ & $\mathbf{1 4 \%}$ \\
No comment & $\mathbf{6}$ & $\mathbf{2 9 \%}$ \\
\hline & & $\mathbf{1 0 0 \%}$ \\
\hline
\end{tabular}


Interestingly, four subjects stated that they hold supplementary certifications besides their basic degrees and post-degree studies. In detail, one subject states that he/she holds a language coach certificate next to a series of other certifications related to human communication and language testing, while the remaining three mention teacher-training certification obtained at British teacher-trainer centers.

\subsection{Coaching Certification Training}

As regards the training in order to receive certification as a language coach, all 21 subjects rendered relevant information. All 21 subjects had undergone significant training in order to receive their language coach certification. Three of the subjects $(14,29 \%)$ stated that their initial studies were not directly related to language teaching, which was the reason why they underwent further language coach training.

Furthermore, nine subjects underwent special supplementary courses in order to enable themselves to function as a language coach. These extra courses included on-line seminars as well as one-to-one training courses and postgraduate courses for language teachers.

\subsection{Professional Details}

A variety of initial professional background can be found in the sample. Most of the responses though showed a distinct professional profile towards language teaching, although there were a few exceptions. The following table depicts the submitted professional background of the sample. The second column attempts to encode the professions and thus summarize the training of the individuals in the third column.

Table 5. Professional Self-Description (discriptive)

\begin{tabular}{|c|c|c|}
\hline Description submitted ${ }^{3}$ & $\begin{array}{c}\text { Occupational } \\
\text { Encoding }\end{array}$ & Count \\
\hline Managing director of a language school & Business Management & 1 \\
\hline Language coach; Doctoral student in a state university in US & Language Coach & 1 \\
\hline English Language Coach & Language Coach & 2 \\
\hline Director for Costa Rica and the Americas at Efficient Language Coaching & Business Management & 2 \\
\hline $\begin{array}{l}\text { Trainer for Business English, Consultant for Facial Expressions Reading } \\
\text { Language Coach }\end{array}$ & Language Coach & 3 \\
\hline English language trainer & Language Coach & 4 \\
\hline Language Coach, Lecturer & Language Coach & 5 \\
\hline "Diplom-Ingenieur (graduated engineer)" & I nnoupos Coach & 6 \\
\hline TEFL teacher/translator & Language coach & $\mathbf{0}$ \\
\hline Psychologist & Other & 1 \\
\hline director/lawyer/language coach & Other & 2 \\
\hline Language Coach & Language Coach & 7 \\
\hline self-employed, coach & Language Coach & 8 \\
\hline I work in Education & Education & 1 \\
\hline English trainer / coach / translator / interpreter & Other & 3 \\
\hline Modern Foreign Languages Teacher & Language Coach & 9 \\
\hline Language and Communication Consultant & Other & 4 \\
\hline Language Coach & Language Coach & 10 \\
\hline Director & Business Management & 3 \\
\hline Lecture & Education & 2 \\
\hline Freelance English language trainer and coach & Language Coach & 11 \\
\hline
\end{tabular}

As Table 5 shows, most of the subjects are occupied in the educational business as Educators or Coaches (in total 13, $\mathrm{n}=21,62 \%$ ), while the remaining individuals represent managerial or other occupations. One response only did not 
specify occupation.

Thus, the resulting break-down of the self-descriptions of occupation of the sample is described in the following Table 6 (percentage rounded to nearest integer)

Table 6. Professional Background (aggregated)

\begin{tabular}{|c|c|c|}
\hline Occupational Encoding & Count & Percentage \\
\hline Business Management & 3 & $14 \%$ \\
\hline Language Coaches & 11 & $52 \%$ \\
\hline Education & 2 & $10 \%$ \\
\hline Other & 4 & $19 \%$ \\
\hline No description submitted & 1 & $45 \%$ \\
\hline Total & 21 & $100 \%$ \\
\hline
\end{tabular}

Referring to the occupational relationship as language coaches, the input of the survey offered the information depicted in Table 7 (percentage rounded to nearest integer). According to the findings, the individuals equally declared to be "freelance" or "self-employed" (38\% each), while the minority $(19 \%)$ mentioned to be full-time employed. One respondee did not submit details of his/her occupational status.

Table 7. Occupational Status

\begin{tabular}{rrrrrr}
\hline freelance & $\begin{array}{c}\text { full-time } \\
\text { employment }\end{array}$ & $\begin{array}{c}\text { part-time } \\
\text { employment }\end{array}$ & self-employed & $\begin{array}{c}\text { no } \\
\text { answer }\end{array}$ & \multicolumn{1}{c}{ Sum } \\
\hline 8 & 4 & 0 & 8 & 1 & 21 \\
$38 \%$ & $19 \%$ & $0 \%$ & $38 \%$ & $5 \%$ & $100 \%$ \\
\hline
\end{tabular}

Of these responses, three individuals submitted further details on their occupational status, mentioning entrepreneurship, occasional freelance occupation and having an own business. The one individual declaring entrepreneurship also mentioned "self-employed" as his/her occupational status, thus reinforcing the submission of his/her status.

\subsection{Professional Aspirations as Language Coach}

In order to research the aspirations for becoming a Language Coach, a series of ten Likert-type questions were issued.

All 21 respondents submitted a variety of reasons, for which they wanted to expand their activities into language coaching. According to the submissions, as can be seen in the following table, five different categories of occupational aspirations could be identified: (1) wanting to help, (2) wanting to combine various teaching approaches, (3) wanting to assist in or be part of personal development, (4) looking for personal add-on opportunities for their business $C V$ and (5) wanting to achieve better efficiency.

Table 8. Added Professional Value

\begin{tabular}{lcr}
\hline Code & Count & Percentage \\
\hline Help & 3 & $11 \%$ \\
Combination & 3 & $11 \%$ \\
Development & 13 & $48 \%$ \\
CV add-on & 6 & $22 \%$ \\
Efficiency & 2 & $7 \%$ \\
\multicolumn{1}{c}{ Sum } & $\mathbf{2 7}$ & $\mathbf{1 0 0 \%}$ \\
\hline
\end{tabular}

All subjects responded to the question about their LC occupation by giving respective information. As can be seen in the following table, the majority of the subjects $(52 \%, \mathrm{n}=21)$ have been occupationally involved in Foreign Language Coaching for one year, while a total of $38 \%$ have practiced LC for more than one year, reaching up to more than 
seven years $(19,05 \%)$. Two only $(9,52 \%)$ of the subjects state that they have not yet started working in the field.

Interestingly, most subjects comment that they had been intuitively using some or most of the neurolanguage techniques mentioned and demonstrated in the certification training of ELC, prior to their actual training as Language Coaches.

Table 9. Previous Occupation

\begin{tabular}{lcr}
\hline Previous LC occupation (in years) & Count & Percentage \\
\hline First year & 11 & $\mathbf{5 2 , 3 8 \%}$ \\
Between one and three years & 2 & $\mathbf{9 , 5 2 \%}$ \\
Between four and seven years & 2 & $\mathbf{9 , 5 2 \%}$ \\
More than seven years & 4 & $\mathbf{1 9 , 0 5 \%}$ \\
Not started yet & 2 & $\mathbf{9 , 5 2 \%}$ \\
\multicolumn{1}{c}{ Total } & 21 & $\mathbf{1 0 0 \%}$
\end{tabular}

Sixteen out of twenty one (76\%) subjects mentioned that they were language coaching for English as a foreign language. From these, two (10\%) claimed language coaching for both English and German. The remaining five (24\%) mentioned a variety of other languages besides English and German.

Table 10. Languages Taught

\begin{tabular}{lrr}
\hline Coaching Language & Count & Percentage \\
\hline English & 16 & $76.19 \%$ \\
German & 2 & $9.52 \%$ \\
French & 1 & $4.76 \%$ \\
Spanish & 2 & $9.52 \%$ \\
Greek (modern) & 0 & $0.00 \%$ \\
Other European language(s) (please specify) & 0 & $0.00 \%$ \\
Arabic languages & 0 & $0.00 \%$ \\
other (please specify) & 2 & $9.52 \%$ \\
\hline
\end{tabular}

Investigating the reasons, for which the subjects had initially wanted to train for neurolanguage coaching, a series of interesting results surfaced. Out of 21 completed questionnaires, sixteen responded to this series of questions, while 5 did not render information to all role-related questions.

For the first question regarding the LC's position as a "role model", 16 responses were submitted. Most subjects (5 responses, $31,25 \%, \mathrm{n}=16)$ did not assent to wanting to be a "role model", while four respondents $(25 \%, \mathrm{n}=16)$ submitted their wish to become a role model for their customers. The mid-point produced two responses $(12,5 \%$, $\mathrm{n}=16)$. A slight tendency towards declining the role $(31,25 \%)$ against supporting it $(25 \%)$ could be monitored.

Most of the respondents, namely twelve out of sixteen $(75 \%, \mathrm{n}=16)$ declined the role of "teacher" or "instructor" as their reason for wanting to become a Language Coach, while the remaining four $(25 \%, \mathrm{n}=16)$ advocated this role positively. The mid-point did not receive any responses, while the two outbound anchor points showed significant variations, since $12,5 \%$ tended toward the negative anchor point, while $6,25 \%$ tended towards the positive.

A limited incentive for taking on the role of Language Coach seems to have been the possibility to assist in conceptual and / or theoretical learning. Out of sixteen responses, five $(31,25 \%, n=16)$ stated that their main reason for wanting to become a LC was to function as assistance in conceptual or theoretical learning, while three responses $(18,75 \%)$ stated that they were against this role. The mid-point value of $25 \%$ levelled the negative response to some point, while the tendency of the respondents clearly was towards the positive anchor, since a total of $50 \%$ responded towards the positive outbound anchor.

Eighteen out of the twenty one subjects responded to the role of "advice-giving". This section evoked mixed responses, since $38,89 \%(\mathrm{n}=18)$ replied negatively, while $44,44 \%$ submitted a positive response. The tendency around the midpoint showed a definite trend toward the positive anchor, implying a tendency towards leadership in respect to language coaching. 
Helping people to acquire language skills through Language Coaching seemed to be the main interest to the subjects. According to the responses of 20 individuals out of 21 completed questionnaires $(95 \%, n=20)$, most of the subjects responded either absolutely $(80 \%)$ or almost absolutely $(10 \%)$ positively to wanting to help others, while there was only one response towards the negative anchor, which together with the mid-point value made up $10 \%$ of the total submitted responses.

Being a "resource person" also accumulated a lot of responses, since 20 out of 21 subjects submitted their answers. Again, most of the individuals $(60 \%, \mathrm{n}=20)$ cited their positive agreement to this role, while $15 \%$ responded towards the negative anchor. The mid-point value of $25 \%$ hinted a neutral position for five subjects.

Functioning as an "executive coach" seemed to be of quite some interest to the subjects, since 18 out of 21 respondents submitted their answer to this question. Here, half of the responding subjects $(50 \%, \mathrm{n}=18)$ stated that their interest lay in this role, positioned mainly towards the positive anchor point. On the other hand, $33 \%$ of the subjects positioned themselves towards the negative anchor point, declining the role of executive coach either totally $(22 \%)$ or mostly $(1 \%)$. The mid-point value provided a mediate value of $17 \%$, hinting moderate neutrality on this issue.

A great number of the respondents also mentioned that one of their main incentives to engage with Neurolanguage Coaching was because they wanted to base their interventions on values. This value-driven incentive was declared by $44 \%(\mathrm{n}=18)$ of the subjects, out of which the most $(39 \%)$ put themselves on the outmost positive anchor, while the opposite remark gathered $17 \%$. Around the mid-point another $44 \%$ positioned themselves towards the neutral anchor, allowing for a general neutral position of this role.

Finally, in contrast to the previous position, most of the subjects $(41 \%, n=17)$ stated that they either did not agree at all or did to some point agree to the role of procedure-based interventions. Here, the mid-point value of $35 \%$ and its surrounding innermost anchors gathered the majority of responses, reaching a total of $82 \%$.

\subsection{Pedagogical Ambitions as a Language Coach}

Examining the ambitions of the subjects to become a Language Coach, a series of five Likert-type questions were set out for the individuals to respond to.

According to the findings, the majority of the subjects $(90 \%, \mathrm{n}=20)$ rendering information stated that their ambition was to make high-functioning individuals perform even better. Only one subject (5\%) declined this ambition, while the mid-point value of 5\% enforces the main stream mentioned by the majority.

Another strong ambition was recovered on the topic of sharing "ideas and expectations about the roles of the coach and coachee". In this instance, an overwhelming $72 \%(\mathrm{n}=18)$ stated their positive attitude to this ambition, while only a small number of subjects (11\%) located themselves on the other half of the mid-point towards the negative anchor. The actual mid-point value of $17 \%$ hints a notion of tendency towards the positive anchor point.

The humanistic approach, which seems to be the main stream indicator of the LC's already certified, was pointed out by the responses to the question on the LC's ambition to "encourage and enable learners to take more responsibility for their own development", which was submitted by all 21 subjects of the survey. Here the subjects submitted a clear perspective of wanting to allow their clients freedom and initiative in their learning. A total of $95 \%(n=21)$ stated their ambition, either in absolute agreement $(76 \%)$ or in high agreement $(19 \%)$, while only one response appointed $\mathrm{him} / \mathrm{h}$ erself on the outmost negative anchor, and no mid-point value was given.

On the other hand, for the question of using "systematic methodology in coaching procedures" just about half of the subjects $(57 \%, \mathrm{n}=21)$ responded towards the outmost positive anchor, admitting to using systematic methodological approaches, while a quite strong tendency (24\%) towards the opposite negative anchor could be witnessed as well. The mid-point value of $19 \%$ hints some neutral disposition towards using specific methodology systematically.

Finally, all subjects of the survey entered their ambition to "use flexible personal methodology in coaching procedures". Here, the majority $(76 \%, \mathrm{n}=21)$ stated their positive disposition towards this ambition. Interestingly, the majority (43\%) did not declare absolute agreement with the ambition. On the other hand, only one individual (5\%) stated disagreement to this ambition, while four subjects ranged in the mid-point (19\%), which offers the impression that the tendency is towards the positive anchor.

\subsection{ICT Approach}

The last item to be examined in the questionnaire was the use of Information and Communication Technologies (ICT) in Neurolanguage Coaching practice. 
According to the findings, the use of ICT seemed to be another major point of interest, since $61 \%$ of the subjects stated some kind of use of ICT. Here, half of the individuals (50\%) expressed their agreement to the use of modern technologies, while another $11 \%$ stated their great interest. On the other hand, 33\%, evenly distributed to the innermost and outermost negative anchor points, stated that their interest was either limited or non-existent. Analyzing the responses and their respective supplementary explanations, ICT technologies like social media, use of on-line videos, youtube videos and other such objects were mentioned.

\section{Discussion and Conclusion}

After completing the analysis of the findings of this survey, the initial research questions can be answered and distinct features of the Foreign Neurolanguage Coach (NLC) can be highlighted.

As the results show, NLCs are not limited to a specific age-group, although it seems that most NLCs range between 35 and 55 years of age. Thus, NLCs tend to be in their mid-40s, which, according to Erikson (1998), generally is considered to be an age of maturity and willingness to shift careers. Corresponding to Erikson's classification of "middle age", this age group attempts to produce something that makes the difference to society, posing generativity against stagnation, because middle adulthood is the time when people take on greater responsibilities. This absolutely conforms to the findings of this study, backed up by the statements for personal and professional ambitions as described in the survey.

On the other hand, nationality or country of origin does not seem to have any specific impact on the professional profile of NLCs.

Although templating education professionals based on their educational and expertise background offers numerous alternative readings, NLC profiles can be narrowed down to very specific characteristics corresponding to the findings of the study. According to the survey, NLCs hold tertiary education degrees with very specific post-degree studies, specializing mainly in language education. According to the submissions, NLCs specialize in Humanities and Language, while their post-degree NLC certification includes scope-oriented seminars and further training. As regards the initial profession of the NLCs, the research showed a clear domination of educational background with a significant number of years of experience in the field. Finally, NLCs obviously function on a self-employed or freelance basis.

Aspirations and ambitions of NLCs show a very specific matrix. The aspirational and ambitious characteristics unveiled by the survey are in concordance with the age-specific classification of Erikson mentioned earlier.

As the submissions indicate, NLCs strive for development, both for themselves and their clients, while the need to assist learning and encourage the coachee through combinations of language teaching techniques tailored according to neuroscience theories are eminent. This specific humanistic character does not seem to be restricted by the years of NLC experience, since the wish to function as a "sounding board" for the coachee is embedded in most responses of the NLCs referring to their professional aspirations. NLCs appear to be liberated from the archetype of "language teacher" who gives instruction and requires "obedience". On the contrary, NLCs tend to be "democratic" leaders who function as a "resource" of a self-regulated learning process which is inaugurated and controlled by the coachee $\mathrm{him} /$ herself.

Finally, NLCs express their ambition to bring out the best functionality of their clients, according to the characteristics again as stated by Erikson's stages of development, at the same time stressing their will to encourage development and the learners' responsibility. They make every effort to achieve this goal by attending to specific Neurolanguage Coaching methodologies combined with traditional language teaching methods, as long as the latter do not interfere with the main objective of allowing the coachee to "govern" his/her learning style and pace. In trying to improve the coachee's learning rate, NLCs do not hesitate to utilize modern ICT technologies to implement various learning styles in order to satisfy their coachee's need for self-regulation.

In short, according to this study, a Neurolinguistic Foreign Language Coach or Neurolanguage Coach ${ }^{\mathrm{TM}}$ is a highly qualified language teaching specialist, holder of at least one tertiary degree and a Neurolanguage Coaching certificate, whose work is characterized by utmost democratic, non-directive approaches in order to propel his client's learning experience by supporting his/her own learning strategies and developing communicational strategies which allow for his client to assimilate new language material without blocking the input due to subconscious defensive actions caused by "invasive" teacher-enforced learning attempts.

As already mentioned in the beginning of this study, this paper is to be considered a case study of language coach 
certification examples based on neurolanguage coaching (as defined in this paper) implemented by ELC. To verify the findings and conclusions of this study, further investigation of certified language coaches using techniques influenced by neuroscientific findings is required. The scientific community is urged to take on this endeavor in order to substantiate and incorporate findings of neurolanguage coaching comprising modern neuroscience in conjunction with neurolinguistic and pedagogical approaches to facilitate language learning for specific purposes.

\section{Acknowledgements}

This paper has been written based on detailed and long-lasting discussions on pedagogical, neuroscientific and methodical issues of language teaching and coaching carried out with Rachel M. Paling, Director of Efficient Language Coaching (ELC), who supported the survey by forwarding the research material to certified language coaches of ELC and ICF through her network of language coaches. Without her substantial assistance and continuous support in addressing diverse issues that arose during the study, for which the author of this paper wishes to express his deepest appreciation, this survey and resulting study could not have been realized. Further acknowledgment is to be mentioned for all colleagues around the world that contributed to this study either by participating in the questionnaire or proof-reading and offering feedback on the final draft of the paper.

\section{References}

Baird, J.-A., Hopfenbeck, T. N., Newton, P., Stobart, G., \& Steen-Utheim, A. T. (2014). State of the Field Review Assessment and Learning (No. 13/4697) (Vol. 13/4697, pp. 1-174). Oxford. Retrieved from http://www.forskningsradet.no/servlet/Satellite?blobcol=urldata\&blobheader=application\%2Fpdf\&blobheadern ame $1=$ Content-Disposition\%3A\&blobheadervalue $1=+$ attachment $\% 3 \mathrm{~B}+$ filename $\% 3 \mathrm{D} \% 22 \mathrm{FINALMASTER} 2 \mathrm{Jul}$ y14Bairdetal2014AssessmentandLearning.pdf\%22\&blobkey $=\mathrm{id} \&$ blobtable $=$ MungoBlobs\&blobwhere $=127450$ 4659961\&ssbinary $=$ true

Bennet, B. (2003). Developmental Coaching - Rejecting the remedial approach. Development and Learning in Organizations, 17(4), 16-19.

Biswas-Diener, R. (2009). Personal coaching as a positive intervention. Journal of Clinical Psychology, 65, 544-553. http://dx.doi.org/10.1002/jclp.20589.

Caccia, P. F. (1996). Linguistic Coaching: Helping Beginning Teachers Defeat Discouragement. Improving Prfoessional Practice, 53(6), 17-20.

Canrinus, E. T., Helms - Lorenz, M., Beijaard, D., Buitink, J., \& Hofman, A. (2011). Profiling teachers' sense of professional identity. Educational Studies, 37(5), 593-608. http://dx.doi.org/10.1080/03055698.2010.539857.

Chen, C. C., \& Jones, K. T. (2007). Blended Learning vs. Traditional Classroom Settings : Assessing Effectiveness and Student Perceptions in an MBA Accounting Course. The Journal of Educators Online, 4(1), 1-15.

Comas-Quinn, A. (2011). Learning to teach online or learning to become an online teacher: an exploration of teachers' experiences in a blended learning course. ReCALL, 23(3), 218-232. http://dx.doi.org/10.1017/S0958344011000152.

Dingen, B. (n.d.). Beyond language - towards communication coaching. Professional English Online. Retrieved July 05, 2014, from http://peo.cambridge.org/index.php?option=com_content\&view=article\&id=178:beyond-language-towards-com munication-coaching-by-bob-dignen \&catid $=3:$ blog \&Itemid $=2$

ERIC - Thesaurus - Profiles. (n.d.). Retrieved July 20, 2014, from http://eric.ed.gov/?ti=Profiles

Erikson, E. H. (1998). The Life Cycle Completed: a review / Extended Version with new chapters by Joan M. Erikson. New York: W.W. Norton \& Company, Inc.

Fichtner, F., \& Chapman, K. (2011). The Cultural Identities of Foreign Language Teachers. L2 Journal, 3(1), 116-140.

Grant, A. M., \& Unit, C. P. (2006). Toward a profession of coaching: Sixty-five years of progress and challenges for the future . International Journal of Evidence Based Coaching and Mentoring, 2, 1-16. Retrieved from $\mathrm{http} / /$ scholar.google.com/scholar?as_q=\&num $=10 \& b \operatorname{tnG}=$ Search+Scholar\&as_epq $=\&$ as_oq $=\& a s$ eq $=\&$ as_occ $\mathrm{t}=$ any\&as_sauthors $=\mathrm{Grant}+\mathrm{Cavanagh} \&$ as_publication $=\&$ as_ylo $=2004 \&$ as_yhi $=2004 \&$ as_sdt $=1$.\&as_sdtp $=0$ on\& as_sdtf $=\&$ as_sdts $=5 \& h l=$ en $\# 0$ 
Greenman, C. (2004). Coaching Academic English through voice and text production models. ReCALL, 16(1), 51-70. http://dx.doi.org/10.1017/S0958344004000515

Griffiths, K., \& Campbell, M. (2009). Discovering, applying and integrating: The process of learning in coaching. International Journal of Evidence Based Coaching and Mentoring, 7, 16-30. Retrieved from http://ezproxy.library.capella.edu/login?url=http://search.ebscohost.com/login.aspx?direct=true\&db=bth\&AN=4 $4774919 \&$ site $=$ ehost-live \&scope $=$ site

Halim, N. D. A., Ali, M. B., \& Yahaya, N. (2011). Personalized Learning Environment: Accommodating Individual Differences in Online Learning. In 2011 International Conference on Social Science and Humanity IPEDR (Vol. 5, pp. 398-400). Singapore: ICSIT Press. Retrieved from http://www.ipedr.com/vol5/no2/88-H10220.pdf

Hamlin, R. G., Ellinger, A. D., \& Beattie, R. S. (2009). Toward a Profession of Coaching ? A Definitional Examination of " Coaching ," "Organization Development," and "Human Resource Development. International Journal of Evidence Based Coaching and Mentoring, 7(1), 13-38.

Hildebrandt, M. (2005). Working definitions of profiling: some distinctions. D7.2: Descriptive analysis and inventory of profiling practices: Future of IDentity in the Information Society. Retrieved July 20, 2014, from http://www.fidis.net/resources/fidis-deliverables/profiling/int-d72000/doc/2/

ICF Foundation. (n.d.). About Coaching. International Coach Federation. Retrieved July 04, 2014, from $\mathrm{http}$ ://foundation.coachfederation.org/AboutCoaching.aspx

Ives, Y. (2008). What is "Coaching"? An Exploration of Conflicting Paradigms. International Journal of Evidence Based Coaching and Mentoring, 6(2), 100-113.

Ives, Y. (2009). Coaching Plain and Simple: Solution-Focused Brief Coaching Essentials. International Journal of Evidence Based Coaching and Mentoring, 7, 104-106. Retrieved from http://www.business.brookes.ac.uk/research/areas/coaching\&mentoring/

Jackson, P. (2005). How do we describe coaching ? An exploratory development of a typology of coaching based on the accounts of UK-based practitioners. International Journal of Evidence Based Coaching and Mentoring, 3(2), 45-60. Retrieved from http://www.business.brookes.ac.uk/research/areas/coaching\&mentoring/

Juwah, C., Macfarlane-Dick, D., Matthew, B., Nicol, D., Ross, D., \& Smith, B. (2004). Enhancing student learning through effective formative feedback. Retrieved from http://www.jisctechdis.ac.uk/assets/documents/resources/database/id353_senlef_guide.pdf

Kirwin, S., Swan, J., \& Breakwell, N. (2009). Comparing Online Learning with Blended Learning in a Teacher Training Program, 5(2), 67-74.

Kormos, J., \& Csizér, K. (2014). The Interaction of Motivation, Self-Regulatory Strategies, and Autonomous Learning Behavior in Different Learner Groups. TESOL Quarterly, 48(2), 275-299. http://dx.doi.org/10.1002/tesq.129

Kovacic, Z. J. (2012). Predicting student success by mining enrolment data. Research in Higher Education Journal, 15, $1-20$. Retrieved

from http://0-search.proquest.com.aupac.lib.athabascau.ca/docview/993157760?accountid=8408\nhttp://aupac.lib.ath abascau.ca:4550/resserv?genre $=$ article $\&$ issn $=\&$ title $=$ Research + in + Higher + Education + Journal $\&$ volume $=15 \&$ iss $\mathrm{ue}=\&$ date $=2012-03-01 \&$ atitle $=$ Predicting + student + success + by + mining + enrolment + data $\&$ spage $=1 \&$ aulast $=$ Kov acic\&sid=ProQ:ProQ:abiglobal\&isbn=\&jtitle=Research + in + Higher+Education + Journal\&btitle=

Lebrun, Y. (1983). Issues in Neurolinguistics. Language Sciences, 5, 241-248. http://dx.doi.org/10.1016/S0388-0001(83)80026-6

Menn, L. (n.d.). Neurolinguistics. Linguistic Society of America. Retrieved from http://www.linguisticsociety.org/resource/neurolinguistics

Myers, A. (n.d.). Language Coaching|The Everyday Language Learner. Retrieved June 22, 2014, from http://www.everydaylanguagelearner.com/language-learning-resources/coaching-2/

Nergis, A. (2011). To what extent does neurolinguistics embody EFL teaching methods? Procedia - Social and Behavioral Sciences, 15, 143-147. http://dx.doi.org/10.1016/j.sbspro.2011.03.064

North, B. (2009). A Profiling Grid for Language Teachers. In International Meeting on Training, Quality and Certification in Foreign Language Teaching Siena, 9-10 February 2009 (pp. 1-11). (European Association for Quality Language Services. 
Onyancha, O. B. (2010). Profiling students using an institutional information portal: a descriptive study of the Bachelor of Arts degree students, University of South Africa. South African Journal of Libraries and InformationSciences, 76(2), 153-167.

Paling, R. M. (2013a). The Differences between Language Teaching and Language Coaching. Efficient Language Coaching

Retrieved

from $\mathrm{http} / /$ www.languagecoachingcertification.com/differences-language-teaching-and-language-coaching

Paling, R. M. (2013b). Transforming Language Teachers into Language Coaches. Efficient Language Coaching. Retrieved

from http://www.languagecoachingcertification.com/transforming-language-teachers-into-language-coaches

Paling, R. M. (2014). The Differences between Language Teaching and Language Coaching. Research Chronicler, 2(6), 13-19.

Rahman, A. (2013). Teacher Assessment and Profiling using Fuzzy Rule based System and Apriori Algorithm. International Journal of Computer Applications, 65(5), 22-28.

Rosinski, P. (2003). Coaching Across Cultures. International Journal of Coaching in Organizations, 1(4), 4-16.

Schoen, A. (2013). Investigating Self-Identification. University of Wisconsin. Retrieved from http://brainimaging.waisman.wisc.edu/ ecwell/ISI/neuroscience.html

Sherris, A. (2009). Disturbing the future: Curriculum change in a kibbutz school. In K. Graves \& L. Lopriore (Eds.), Developing a new curriculum for school-age learners (pp. 89-106). Alexandria, VA: Teachers of English to Speakers of Other Languages.

Sherris, A. (2010). Coaching Language Teachers. CAL Digest, (July). Retrieved from http://www.cal.org/resources/digest/digest_pdfs/coaching-language-teachers.pdf

Sherris, A., Bauder, T. A., \& Hillyard, L. (2007). The lay of the land. In An insider's guide to SIOP coaching (pp. 3-13). Washington, DC: Center for Applied Linguistics.

Showers, B., \& Joyce, B. (1996). The Evolution of Peer Coaching. Improving Professional Practice, 53(6), 12-16.

Stewart, L. J., Palmer, S., Wilkin, H., \& Kerrin, M. (2008). The Influence Of Character : Does Personality Impact Coaching Success? International Journal of Evidence Based Coaching and Mentoring, 6(1), 32-42.

Tayebinik, M., \& Puteh, M. (n.d.). Blended Learning or E-learning? Retrieved January 02, 2013, from http://arxiv.org/ftp/arxiv/papers/1306/1306.4085.pdf

Yukselturk, E., \& Yildirim, Z. (2008). Investigation of Interaction, Online Support, Course Structure and Flexibility as the Contributing Factors to Students ' Satisfaction in an Online Certificate Program. Educational Technology \& Society, 11, 51-65.

Zampetakis, L. A., Bouranta, N., \& Moustakis, V. S. (2010). On the relationship between individual creativity and time management. Thinking Skills and Creativity, 5(1), 23-32. http://dx.doi.org/10.1016/j.tsc.2009.12.001

Zeppos, D. (2014). A Case Study On Student Satisfaction For Graduates Of The German Language Teachers' Blended Ma Program Of The Hellenic Open University, Classes Of 2012 And 2013. Turkish Online Journal of Distance Education, 15(4), 48-74.

\section{Notes}

Note 1. The comments mentioned are taken from the input table of the survey "as is" without any alterations.

Note 2. Personal details have been submitted in this response but are not shown in this table.

Note 3. The descriptions mentioned in the first column are taken from the input table of the survey "as is" without any alterations. 